\title{
Conduct and utilization of research among nurses at federal capital territory, Abuja Nigeria
}

\author{
Abimbola Oluwatosin \\ University of I badan, I badan, Nigeria. \\ Correspondence: Abimbola Oluwatosin. Address: University of I badan, I badan, Nigeria. Email: aoluwatosin@yahoo.com \\ Received: February 10, 2014 \\ Accepted: April 10, $2014 \quad$ Online Published: May 14, 2014 \\ DOI : $10.5430 /$ jnep.v4n7p139 \\ URL: http://dx.doi.org/10.5430/jnep.v4n7p139
}

\section{Abstract}

Background: The need to support nursing practice with evidence and the demand for quality care have implications for conduct of research by nurses for nursing. Research findings are required to determine or establish evidence for practice. This study assessed how nurses conduct and utilize research.

Methods: A cross sectional survey design was utilized to explore registered nurses' conduct and utilization of research. A structured questionnaire was distributed to 325 nurses from various health care institutions in the Federal Capital Territory, Abuja Nigeria. Data were analyzed using frequency and cross tabulations.

Results: Only 21.2\% had conducted research based on their clinical experience while just $4.4 \%$ had published in peer reviewed journals and 31.4\% had utilized research findings in clinical practice. Few of the respondents, 19.2\%, considered time related issues as the leading barrier; while the leading factors that facilitated research were "financial support, motivation and incentive". Most (74.1\%) of the respondents conducted research only to fulfill certificate or degree requirements. Less than half (41.2\%) believed that they possessed the skill to conduct a good literature search.

Conclusions: Conduct and utilization of research was very poor within the study population. Only few of the research conducted were also published in peer reviewed journals. It is recommended that identified barriers should be addressed to improve conduct and utilization of research.

\section{Key words}

Barriers and facilitators, Conduct of research, Nurses, Nigeria, Utilization of research

\section{I ntroduction}

Historical trends reveal that research in nursing began with Florence Nightingale in 1859. Her most notable contribution was the study of factors affecting soldiers' mortality and morbidity during the Crimean War ${ }^{[1]}$. Several Nurse authors ${ }^{[1-4]}$ opined that nurses are increasingly expected to understand and conduct research as well as base professional practice on emerging evidence from research. Research is viewed in most professional circles as necessary for the development of the scientific body of knowledge, which is the hallmark of a profession ${ }^{[5]}$. The International Council of Nurses (ICN) about fifteen years ago, also stated that research based practice is the hallmark of professional nursing, and that nursing research is critical for quality cost effective health care ${ }^{[5]}$. This statement was reiterated in 2009 and in addition it was stated that ICN "facilitates and promotes the conduct, dissemination, and utilization of research related to nursing, health and health care systems" ${ }^{[6]}$. 
There is a global challenge to health care professionals to justify the evidence base for their decisions ${ }^{[3]}$. Evidence based practice however demands that clinical practice should be based on sound research evidence about the effectiveness of health care procedures. To be able to meet this global demand, nurses need to conduct research. Evidence based practice that will improve the quality of nursing care and maximize health outcomes and cost effectiveness of nursing interventions is dependent on knowledge generated through nursing research ${ }^{[6]}$. The implication of this therefore is that nurses should conduct research in the area of health, illness and delivery care services. They should also utilize research findings to improve nursing care. Several factors are associated with conduct and utilization of research. These include individual, organizational and contextual factors ${ }^{[4]}$. Beliefs, attitudes, education, information seeking and professional characteristics were also reported to be associated with research utilization ${ }^{[4]}$. However, an individual cannot implement new ideas except if the organization formally accepts such. Another study ${ }^{[5]}$ also indicated a significant correlation between education, participation in research and position as well as research attitude.

A study in the Southern part of Nigeria reported significant relationship between educational level and knowledge base of research. In the same study, 50\% of the respondents held positive attitudes towards research conduct and utilization, and $40.8 \%$ reported utilizing findings frequently. Inability to understand research reports and statistics were identified as barriers ${ }^{[7]}$. Another author considered that ethical dilemmas of the nurse in terms of caring demands and demands of research inquiry may affect nurses' conduct of research ${ }^{[8]}$.

Time constraints, lack of awareness of available research literature, insufficient authority to change practice, inadequate skill in critical appraisal, lack of support for implementation of research findings have also been reported as barriers to research utilization ${ }^{[9,10]}$.

There are several published works on nurses' knowledge and attitude to research, as well as perceived factors influencing utilization of research in the literature ${ }^{[3,5,7,11,12]}$. However there is a dearth of information on studies that explored publication of research by nurses in particular. Research findings in other fields may be applicable to nursing practice. However it is unlikely that other professionals will conduct research that is solely based on nursing problems. Hence nurses need to brace up to the challenge of conducting research. It is therefore pertinent to explore the conduct and utilization of research among nurses.

\subsection{Purpose of research}

To assess the conduct and utilization of research among registered nurses at the Federal Capital Territory (FCT) Abuja, Nigeria.

\subsection{Specific objectives}

- To evaluate if nurses at FCT conduct research.

- To assess utilization of research by nurses in hospitals at FCT.

- To identify those factors that facilitate conduct and utilization of research among nurses.

- $\quad$ To identify barriers to conduct and utilization of research among nurses

\section{Methods}

\subsection{Design/ sampling}

This was a cross sectional survey conducted among nurses in selected government owned hospitals and primary health care settings. Ethical approval for conduct of the study was obtained from Federal Capital Territory (FCT) Health Research Ethics Committee. A calculated sample size plus 15\% attrition rate informed the distribution of 325 questionnaires proportionately to the selected government institutions at FCT Abuja. 


\subsection{I nstrument}

The instrument was a questionnaire developed by the researcher after vast literature review. It had structured and open ended questions. Face and content validity were ascertained by two nursing faculty members and one senior nursing staff with MSc nursing degree at the continuing education unit of the University College Hospital, Ibadan. Reliability of the instrument was carried out using the test-retest method, with about 15 nurses at the University College Hospital. The correlation coefficient value was 0.08. The questionnaire consisted of sections A and B. Section A assessed the socio-demographic data of the respondents while section B consisted of a total of 17 items, nine of which explored the participants' experience with issues of conduct and utilization of research. Three items assessed participants' exposure to journal articles and five others examined their experience with utilization of research.

\subsection{Method of data analysis}

Data analysis was conducted using descriptive statistics of frequency and cross tabulations through SPSS version 20. Frequencies and percentages were computed for socio demographic characteristics as well as participants' utilization and conduct of clinical based research. The various responses that indicated factors that facilitate conduct and utilization of research as well as barriers were listed by respondents on a priority scale of $1-3$. The responses were categorized to six subthemes which are time-related, knowledge-related, finance-related, institutional issues, lack of utilization as well as lack of interest. Frequencies and percentages were computed for each priority scale.

Also on a priority scale of 1-5, participants made recommendations to enhance conduct and utilization of research. The various responses were recoded to six and labeled 1-6 based on highest frequency of recommendation. The six categories were:

- $\quad$ Support (financial support, motivation and incentive for researchers),

- Adequate Resources (Adequate provision of necessary resources for conduct and utilization of research: time, good records, increased staffing, good library facilities),

- $\quad$ Educational (continuing education, study leave for degree, seminar and workshop),

- Mandatory option (research should be made mandatory for all cadres of Nurses, may be considered as criterion for promotion).

- Working relationships (collaboration between Nurses in academia and among working Nurses in practice, establishment of research committee).

- $\quad$ Practice oriented (clients' understanding and awareness of their part in research and integration of findings into practice to benefit clients).

\subsection{Procedure of data collection}

Data collection commenced after ethical approval by the Federal Capital Territory Health Research Ethics Committee. Two senior nurses on their post graduate studies were trained by the researcher to collect data for the study. The Deputy Director Nursing (DDN) and charge nurse of each unit gave permission before distribution of questionnaire to nurses in their units. The Charge Nurse of each unit was left with questionnaires which included a cover page describing the study for the number of nurses in the unit. The nurses that were willing to participate in the study collected, read and signed the consent form and completed the questionnaire. The questionnaire along with signed consent form was returned to the charge nurse after completion and the research assistants collected the ones that were filled and those that were not filled. However some nurses collected the questionnaire but did not submit. The questionnaires that were not collected by nurses who were not willing to participate were also returned to the research assistants by the charge nurse. Anonymity of participants was maintained. Data collection occurred over a period of two and a half months. A total of 325 questionnaires were distributed to nurses in one teaching hospital, two general hospitals, three district hospitals, and three primary health care units proportionately. 


\section{Results}

Out of 325 questionnaires distributed 225 were returned for a 78.5\% response rate. Though some questions were not answered, there was sufficient information for data analysis.

\subsection{Socio-demographic variables}

The mean $( \pm S D)$ age of respondents was $40.2( \pm 8.4)$ years. The mean $( \pm S D)$ years post RN qualification was $16.9( \pm$ 7.7) years, Mean ( \pm SD) years of work experience post RN was $14.8( \pm 8)$ while mean ( \pm SD) years of experience in current place of work was $7.6( \pm 6.1)$. State owned schools predominated among the training institutions for both general nursing and midwifery training. Nursing officer position was the mode of nursing cadres. There were 76 (29.8\%) nursing officers. In Nigeria the entry point for nursing employment after graduation is the nursing officer cadre. The director of nursing position is the highest and this is a managerial position usually for only one nurse. In all there are seven different cadres for nurses apart from the Director of nursing position as shown in Table 1.

Table 1. Socio demographic variable of participants

\begin{tabular}{|c|c|c|}
\hline Variable & Frequency $(\mathrm{N}=255)$ & $\%$ \\
\hline \multicolumn{3}{|l|}{ Sex } \\
\hline Female & 192 & 75.3 \\
\hline Male & 62 & 24.3 \\
\hline \multicolumn{3}{|l|}{ Age group } \\
\hline 22-30years & 43 & 16.9 \\
\hline $31-40$ & 59 & 23.1 \\
\hline $41-50$ & 90 & 35.3 \\
\hline $51-60$ & 19 & 7.5 \\
\hline \multicolumn{3}{|l|}{ Marital Status } \\
\hline Single & 47 & 18.4 \\
\hline Married & 183 & 71.8 \\
\hline Separated & 1 & 0.4 \\
\hline Divorced & 5 & 2.0 \\
\hline widowed & 12 & 4.7 \\
\hline \multicolumn{3}{|l|}{ School of Nursing attended } \\
\hline Teaching Hospital & 67 & 26.3 \\
\hline State Hospital & 81 & 31.8 \\
\hline Mission Hospital & 39 & 15.3 \\
\hline \multicolumn{3}{|l|}{ School of Midwifery attended } \\
\hline Teaching Hospital & 34 & 13.3 \\
\hline State Hospital & 64 & 23.9 \\
\hline Mission Hospital & 43 & 16.9 \\
\hline \multicolumn{3}{|l|}{ Current Position } \\
\hline Nursing Officer & 76 & 29.8 \\
\hline Senior nursing officer & 31 & 12.2 \\
\hline Principal nursing officer & 52 & 20.4 \\
\hline Assistant Chief Nursing officers & 28 & 11.0 \\
\hline Chief Nursing officers & 45 & 17.6 \\
\hline Assistant Director of Nursing & 3 & 1.3 \\
\hline Deputy Director of Nursing & 0 & 0 \\
\hline \multicolumn{3}{|c|}{ Post RN Years of clinical Experience } \\
\hline 1-5years & 39 & 16.7 \\
\hline 6-10years & 34 & 14.5 \\
\hline 11-15years & 57 & 24.4 \\
\hline 16-20years & 42 & 17.9 \\
\hline 21-25years & 36 & 15.4 \\
\hline 26-30years & 24 & 10.3 \\
\hline 31-35years & 2 & 0.9 \\
\hline
\end{tabular}


Only 23(9\%) of the participants had a bachelor's degree in Nursing and five others had M.Sc. Nursing. No participant had other non - nursing university degrees. Table 1 provides details of demographic characteristics of the respondents.

\subsection{Conduct of research/ Publication of research}

One hundred and ten participants (43.1\%) were able to correctly define research as "scientific investigation or enquiry, a process of scientific enquiry or gathering of data and facts about a defined problem for analysis". One hundred and eighty nine $(74.1 \%)$ had conducted research to fulfill certificate or degree requirements. One hundred and fifty nine participants (62.4\%) had observed research ideas in their clinical practice. However only 54 (21.2\%), had conducted research based on experience in clinical practice. Forty three (16.9 \%) indicated how many clinical based researches they had conducted. Twenty two have conducted only one clinical based research, 13 have conducted only two while only one participant have conducted up to five clinical based research, Figure 1 provides other details.

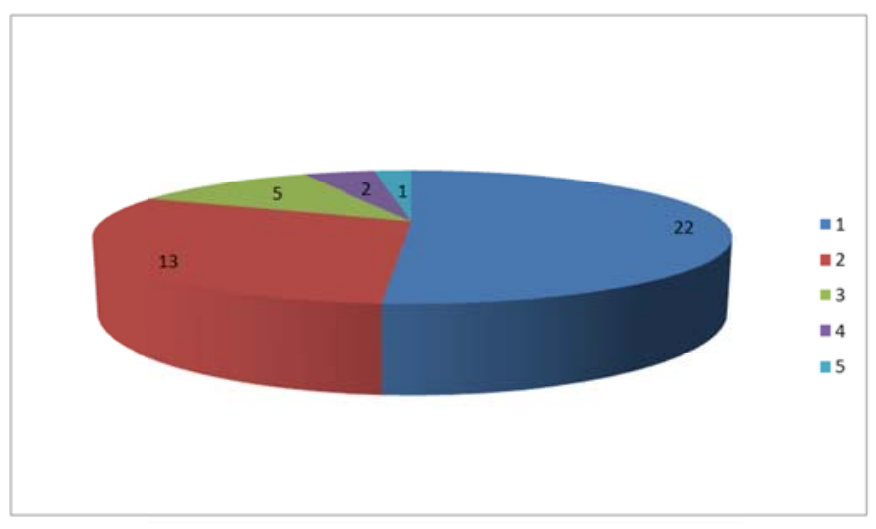

Figure 1. Frequency of clinical based research conducted by respondents

Only 10 of these were reported to have been published in peer reviewed journals. Five respondents had published one paper each; two other respondents had published two and three papers each.

\subsection{Skills of conduct and utilization of research}

One hundred and five (41.2\%) participants believed they possessed the skills necessary to conduct a good literature search. Eighty (31.4\%) of the participants affirmed that they had utilized research findings in clinical practice; 49 of these indicated different areas where such had been implemented, 19 indicated use of research finding in resuscitation, nine mentioned wound care, others were non -specific. More than half, 151 (59.2\%), indicated they had never utilized research findings in clinical practice. The Nigerian Nursing Journal, official Journal of the National Associations of Nigerian Nurses and Midwives was the most widely read journal with a frequency of 38 (14.9\%), 5.5\% were not specific since they just indicated Nursing journals; $4.7 \%$ read Nursing Digest. The official journal of the Nursing and Midwifery Council of Nigeria was read by only $3.1 \%$. Forty four (57.9\%) of the 76 journals listed were read by only one respondent each.

\subsection{Organizational preparedness}

One hundred and forty seven participants (57.6\%) reported that their health institutions did not have protocol for utilization of research. Eighty (31.4\%) indicated that they were aware of evidence based nursing practice models, however none of these were able to correctly list any evidence based models. Forty nine (61.3\%) out of the 80 participants referred to the nursing process as an evidence based nursing practice model.

\subsection{Challenges of conducting research in clinical practice}

Several challenges to conducting research were identified by participants. These were categorized into six; time-related, knowledge-related, finance-related, institutional issues, lack of utilization, and lack of interest. The challenges were listed 
in order of priority on a scale of 1-3. One hundred and thirty six (53.3\%) considered the various factors as priority one challenges. Forty nine (19.2\%) considered time-related issues as the leading challenge; 30 (11.8\%) considered finance, while only 22 (8.6\%) considered lack of knowledge of research as priority one challenge. Figure 2 shows the details.

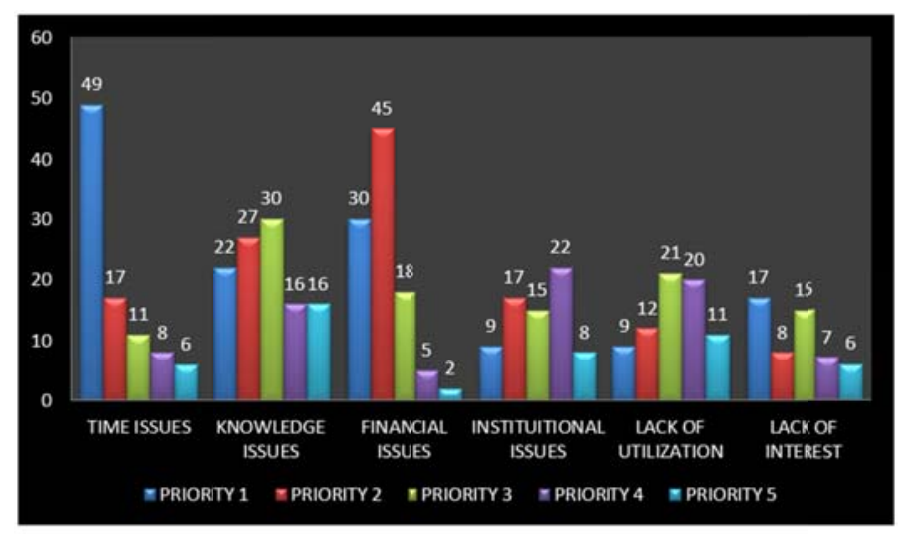

Figure 2. Challenges of Conduct of Research in order of priority

\subsection{Recommendations to enhance conduct of research/ facilitators}

The participants were asked to make recommendations to improve nurses' ability to conduct research in clinical practice; the suggestions were recoded to the six categories below. The most recurring recommendation was tagged recommenddation 1 and other recommendations were listed in the order of frequency of occurrence.

Recommendation 1, Support (financial support, motivation and incentive for researchers): had a total frequency of 104 and also had highest first priority frequency while it was listed 30 and 31 times as first and second priority respectively. Recommendation 2, Adequate resources (adequate provision of necessary resources for conduct and utilization of research: time, good records, increased staffing, good library facilities). Recommendation 3, Educational (continuing education, study leave for degree, seminar and workshop to improve knowledge and enhance conduct of research. Recommendation 4, Mandatory option (conducting research should be made mandatory for all cadres of Nurses, may be considered as criteria for promotion). Recommendation 5, Working relationship (collaboration between Nurses in academia and Nurses in practice, establishment of research committee in hospitals) and recommendation 6, Practice oriented (orientation of clients' about their role in cooperating with nurse researchers, and integration of research findings into practice to benefit clients). Table 2 shows details of recommendations of factors that will enhance conduct of research.

Table 2. Respondents' recommendation for enhancement of conduct of research

\begin{tabular}{lllllll}
\hline Recommendation & Priority 1 & Priority $\mathbf{2}$ & Priority 3 & Priority 4 & Priority 5 & Total \\
\hline Recommendation 1 & 30 & 31 & 23 & 15 & 5 & 104 \\
Recommendation 2 & 12 & 21 & 23 & 10 & 4 & 70 \\
Recommendation 3 & 21 & 21 & 18 & 4 & 5 & 69 \\
Recommendation 4 & 24 & 5 & 9 & 9 & 8 & 55 \\
Recommendation 5 & 11 & 14 & 5 & 9 & 2 & 41 \\
\hline
\end{tabular}

Key: Recommendation 1: Support (Financial support, motivation and incentive for researchers.)

Recommendation 2: Adequate Resources (Adequate provision of necessary resources for conduct and utilization of research: Time, good records, increased staffing, good library facilities)

Recommendation 3: Educational (Continuing education, study leave for degree, seminar and workshop to improve knowledge and enhance conduct of research)

Recommendation 4: Mandatory Option (Research should be made mandatory for all cadres of Nurses, may be considered as criteria for promotion) Recommendation 5: Working Relationship (Collaboration between Nurses in academia and among working Nurses in practice, establishment of research committee)

Recommendation 6: Practice Oriented (Orientation of clients about their role in cooperating with nurse researchers, and integration of research findings into practice to benefit clients). 


\section{Discussions}

The gender structure of the participants is typical of any study with nurses as respondents, females being in the majority ${ }^{[3,7,11]}$. The educational structure was also similar to that of other studies in Nigeria ${ }^{[7,11,12]}$ where very few of the respondents had degree or postgraduate education in Nursing. This is an indication that integration of nursing education into university is still lagging behind as major work force of nurses had diploma education. However, a study among nurses in China ${ }^{[3]}$ reported that almost half of the study population had a bachelor's degree or above.

Most of the researches conducted by respondents were conducted to fulfill requirements for award of certificate. This suggests that the culture of conduct of research remains alien to nurses in the study setting. A lot needs to be done to motivate nurses to see research as an integral part of nursing practice. This finding corroborates the reports of previous studies from Nigeria almost three decades ago where nurses' conduct of research were majorly school based research ${ }^{[12]}$. Only very few (16.9\%) respondents in the current study had participated in clinical research. This is similar to the report of a study in China where only $15.6 \%$ of the study respondents participated in clinical research ${ }^{[3]}$. It is surprising that even in the China study ${ }^{[3]}$ where the number of nurses with bachelor's degree or more were almost $50 \%{ }^{[3]}$ very few of the nurses conducted clinical research. This is similar to the experience of conduct of clinical research in the current study where only 9\% had a bachelor's degree. This contradicts the report of a systematic review on research evidence utilization that identified that educational level among other socio-demographic factors may affect nurses' perception of the value of research ${ }^{[13]}$. This pattern of non -participation in research apart from school based research calls for a need to devise motivating factors to encourage nurses’ participation in research after graduation.

Publication of research reports among nurses in this study was very low as only 10 (3.9\%) of the study participants had published in peer review journals. It shows that even the research conducted to fulfil certificate or degree requirement were not published. Studies that assessed number of publications, types of journals utilized for publication and the quality of publications in peer review journals by nurses are rare. It is recommended that this aspect should be investigated when exploring research issues among nurses. Conduct of research without publication will not provide evidence for practice. It is also vital that there should be clarity in communication if research findings are to impact practice. It has been reported that quality and communication of research findings have been frequently rated as the second most important set of nurses' perceived barriers ${ }^{[3]}$.

Participants in this study were referring to the nursing process as evidence based model. This is a reflection of the organization preparedness for research utilization because if the institution had policy on research utilization, it is expected that nurses will not consider nursing process as evidence based nursing practice models. It is also an indication that there is lack of understanding of the nursing process.

Exposure to nursing journals will provide access to previous studies and this should generally motivate and initiate nurses to conduct research. The finding of this study corroborates previous findings ${ }^{[7]}$ that majority of respondents was not familiar with and did not read nursing journals. About a quarter of the respondents in the same study considered that "nurses were too busy delivering care to spend time reading research materials" It is not surprising therefore that more than half of the respondents in the current study had never utilized research findings in clinical practice.

The most widely read journal among the respondents was the official journal of the National Association of the Nurses and Midwives of Nigeria though by very few, only about $15 \%$ of respondents. A previous study ${ }^{[11]}$ among physical therapists has shown that those having a post- baccalaureate professional degree or an advanced doctorate as their highest degree were more likely to be familiar with online databases. It may be necessary that future studies among nurses be directed at nurses with postgraduate education in nursing to explore whether the response to research among this group will be different.

In this study the identified challenges to conduct research have been identified in various studies as barriers to conduct of research or more frequently as barriers to research utilization. Similar to the previous studies ${ }^{[3,5]}$ where insufficient time 
on the job to implement new ideas topped the list of barriers to research utilization, time related issues were the foremost challenge for conducting research listed in the current study. Time limitations were also implicated in another study that explored nursing research and participants' recruitment ${ }^{[15]}$. Lack of time to implement new ideas and read research was also one of the factors considered as worldwide barriers perceived by nurses. However finance related issues did not come up as barrier to conduct or utilization of research in studies among nurses in developed countries where funding and grants were available to support research. In another study among nurses in Ibadan, Nigeria ${ }^{[12]}$, financial related issues topped the list of barriers, followed by inadequate knowledge and then time related issues. Lack of knowledge of research has been implicated as a barrier for conducting research and research utilization in several studies ${ }^{[3,5,11,12]}$. There is urgent need to explore curriculum content of nursing research in all nursing training programs with due consideration for various barriers identified in the literature.

Respondents in this study made recommendations on what they considered would enhance conduct of research in clinical practice. Financial support, motivation and incentives for researchers were grouped together and this category rated as top priority. In developing countries financing research is a major constraint as researchers often fund their studies, putting strain on a family income which is already thinly stretched. Nurses that are within academic faculties usually are the few conducting research, as their promotion to next level is dependent on publication. Previous studies in Nigeria have also

reported this ${ }^{[7,11]}$. It is not surprising that one of the recommendations made by the respondents was that research should be made mandatory for all cadres of nurses and may be considered a criterion for promotion. This corroborates previous study findings ${ }^{[7]}$ howbeit very few were in support of such a criterion. Other recommendations were made to ensure improved research knowledge. Such included study leave to support further studies to earn a bachelor degree. Various studies ${ }^{[5,7,11,12]}$ from Nigeria have suggested that a bachelor's degree in nursing has not enhanced conduct of research. It is therefore suggested that future studies should explore conduct and utilization of research among nurses with post graduate nursing degree.

\section{Conclusion}

In conclusion, the major barriers and recommendations made by respondents in this study are very important. This is so because such were found to be recurrent in literature. Hence it is essential that these should be addressed at individual, educational/curriculum and health services level to ensure conduct, utilization of research as well as establishment of evidence based nursing practice.

\section{References}

[1] Polit DF, Beck CT. Introduction to Nursing Research in an Evidence- Based Practice environment in Nursing Research , Generating and Assessing Evidence for Nursing Practice. 8th edition. Edited by Polit DF, Beck CT. Philladelphia: Lippincott Williams and Wilkins. 2008; 3-27.

[2] Hall PP. Development of Nursing Research. In Nieswiadomy RM (ed) Foundations of nursing research. 3rd edition. New Jersey: Upper Saddle River. 2008; 1-25.

[3] Chien W.T, Bai Q, Lu X. Nurses perceived barriers to and facilitators of research utilization in Mainland China: A cross- sectional survey. Open Nursing Journal. 2013; 7: 96-108. PMid:23919099 http://dx.doi.org/10.2174/1874434601307010096

[4] Meijers JM, Janssen MAP, Cummings GG, Wallin L, Estabrooks CA, Halfens RYG. Assessing the relationships between contextual factors and research utilization in nursing: systematic literature review. Journal of Advanced Nursing. 2006; 55(5): 622-635. PMid:16907795 http://dx.doi.org/10.1111/j.1365-2648.2006.03954.x

[5] Olade RA. Attitudes and factors affecting Research utilization. Nursing Forum 2003; 30(4): 5-15. http://dx.doi.org/10.1111/j.0029-6473.2003.00005.x

[6] International Council of Nurses (ICN) 2009, Nursing Research a tool for action. Nursing Matters Fact sheet 2009.

[7] Ofi B, Sowunmi L, Edet D, Anarado N. Professional nurses' opinion on research and research utilization for promoting quality nursing care in selected teaching hospitals in Nigeria. Int J Nurs Pract. 2008; 14(3): 243-255. PMid:18460066 http://dx.doi.org/10.1111/j.1440-172X.2008.00684.x 
[8] Fouka G, Mantzorou M. What are the major ethical issues in conducting research: Is there a conflict between the research ethic and the nature of Nursing? Health Sciences Journal. 2011; 5(1): 3-14.

[9] Hutchinson AM, Johnston L, Bridging the divide: a survey of nurses' opinions regarding barriers to and facilitators of research utilization in practice setting. J Clin. Nurs. 2004; 13(3): 304-15. PMid:15009333 http://dx.doi.org/10.1046/j.1365-2702.2003.00865.x

[10] Morse KJ, Editoria: Evidence- based practice links, research, experience, patient needs. Nursing Critical Care. 2006 ; $1(4)$ : 6. http://dx.doi.org/10.1097/01244666-200607000-00001

[11] Oluwatosin OA, Obilor HNC. Nurses’ Knowledge, attitude and perception of factors that influence development and utilization of research in the clinical setting. International Professional Nursing Journal. 2012; 10 (3): 7-13.

[12] Olade RA. Survey of Nursing Research in Nigeria. International Nursing Review. 1990; 37 (4): 299-302. PMid:2228464

[13] Squires JE, Estabrooks CA, Gustavsson P, Wallin L. Individual determinants of research utilization by nurses: a systematic review update. BMC Implement Sci.

[14] Hill JC, Ogilvie L, Carlson DV, Ferland A, Hemingway, Jette DU, et al. Evidence-Based Practice: Beliefs, Attitude Knowledge, and Behaviors of Physical Therapists. PHYS THER. 2003; 83: 786-805. PMid:12940766

[15] Weierbach FM, Glick DF, Fletcher K, Rowlands A, Lyder CH. Nursing Research and participant recruitment: organizational challenges and strategies. J Nurs Adm. 2010; 40(1): 43-48. PMid:20010377 http://dx.doi.org/10.1097/NNA.0b013e3181c97afb 